\title{
Trabalho como subsistência nos hospitais públicos brasileiros
}

\author{
Work as subsistence in Brazilian public hospitlas \\ Trabajo como subsistencia en hospitales publicos brasileños
}

\begin{abstract}
Helena Heidtmann Vaghetti', Maria Itayra Padilha', Rosimeri Carvalho da Silva", Jorge Manuel Trigo de Almeida Simões'II

'Universidade Federal de Santa Catarina. Grupo de Estudos de História do Conhecimento de Enfermagem. Florianópolis, SC

"Universidade Federal de Santa Catarina. Departamento de Ciências da Administração. Florianópolis, SC I'Universidade de Aveiro. Aveiro, Portugal
\end{abstract}

Submissão: 20/04/2008

Aprovação: 10/11/2009

\section{RESUMO}

Trata-se de uma pesquisa de revisão Que objetivou re-interpretar a interpretação de autores de teses e dissertações sobre os significados expressos por trabalhadores da saúde, acerca das relações de subsistência com o seu trabalho, na cultura organizacional de hospitais públicos brasileiros. A investigação ocorreu a partir de teses e dissertações produzidas em programas de pós-graduação (2002/2006). $\mathrm{O}$ referencial teórico-metodológico apoiou-se na antropologia interpretativa defendida por Clifford Geertz. Os resultados apontam Que as relações de subsistência conduzem à alienação do trabalho e a remuneração gera insatisfação econômica Que alavanca a necessidade de outros empregos. A estabilidade no trabalho alimenta o descomprometimento e ações que estimulam a transgressão de normas e facilitam os autogovernos em hospitais públicos brasileiros.

Descritores: Hospitais públicos; Cultura organizacional; Administração de recursos humanos em hospitais; Administração hospitalar.

\section{ABSTRACT}

That was a review study that aimed to analyze the interpretations that authors of dissertations and thesis about the meanings expressed by health workers, about the relations of subsistence with the job, in the organizational culture of public hospitals in Brazil. Data were extracted from from dissertations and theses in the period from 2002 to 2006. The theoretical methodological reference laid in the interpretive anthropology by Clifford Geertz. The results point that the subsistence relations conduct to alienation from work. The payment generates economic non satisfaction that pry the need to have other jobs. The work stability feeds the disengagement and actions that stimulates the transgression of standards and help the own governs in public hospitals in Brazil.

Descriptors: Public hospitals; Organizational culture; Personnel administration, hospital; Hospital administration.

\section{RESUMEN}

Se trató de una revisión Que objetivó re-interpretar la interpretación de los autores de tesis y disertaciones sobre los significados de las relaciones de subsistencia entre los trabajadores de la salud y su trabajo en la cultura organizacional de los hospitales públicos brasileños. La investigación fue realizada a partir de tesis y disertaciones producidas en programas de posgraduación (2002/2006). Como referencial teórico metodológico se empleó la antropología interpretativa defendida por Clifford Geertz. Los resultados señalan Que las relaciones de subsistencia se concilian con la alienación del trabajo y Que la remuneración es símbolo de insatisfacción económica traducida en una cultura de múltiples empleos. La estabilidad laboral alimenta la falta de compromiso con el trabajo, favoreciendo la transgresión de normas por los autogobiernos

Descriptores: Hospitales públicos; Cultura organizacional; Administración de personal en hospitales; Administración hospitalaria. 


\section{INTRODUÇÃO}

Segundo o Relatório Mundial da Saúde, em 2006, existiam no mundo 59 milhões de trabalhadores de saúde distribuídos de forma desigual entre os países e dentro deles. Já nas Américas, este número era de 21.740 .000 , com uma densidade de 24.8 trabalhadores por 1.000 habitantes $^{(1)}$. No Brasil, em 2002, haviam 729.742 trabalhadores do SUS de nível superior, 624.324 de nível técnico/ auxiliar, 244.791 de nível elementar e 581.71 I exercendo atividades administrativas $^{(2)}$. Os Hospitais Universitários Federais ligados diretamente às Instituições Federais de Ensino Superior, contavam, em 2007, com 64.765 trabalhadores incluindo o pessoal das áreas da saúde e administrativa ${ }^{(3)}$

Estes números indicam apenas a Questão Quantitativa e não conseguem, evidentemente, revelar as complexas relações dos trabalhadores da saúde nos hospitais. Entre estas se encontram as relações com o trabalho, em Que os sujeitos, através de suas subjetividades, valores e crenças produzem significados sobre seu trabalho, Que se traduzem em reações Que oscilam entre dedicação e descompromisso, desalento e satisfação, apego e negligência. Estas reações organizam-se em torno de três tipos de relações dos trabalhadores com o seu trabalho denominadas de subsistência, vínculo e resistência ${ }^{(4)}$.

As relações de subsistência entre os trabalhadores da saúde e seu trabalho, mote deste estudo, são aquelas em que as pessoas trabalham somente para suprir suas necessidades econômicas e se encontram descontentes, desmotivadas e com baixo ou nenhum envolvimento com suas atividades nos hospitais.

Os indivíduos Que vêem o trabalho apenas como aquele lugar onde recebem seus salários não encontram razão naQuilo Que fazem e, desta forma, estão continuamente Queixosos, consideram Que ganham menos do Que merecem, comparam seu salário aos de outros e sentem-se continuamente injustiçados ${ }^{(5)}$. Estes problemas afetam a organização e a produção do trabalho e o atendimento/ cuidado/assistência prestada nos hospitais, além de delinear toda a realidade nesses espaços. As ações e reações decorrentes das relações de subsistência no cotidiano dos hospitais são expressas por significados construídos e partilhados social e historicamente pelos trabalhadores e indicam como estes percebem, sentem, raciocinam, julgam e agem em seu trabalho(4). A interpretação desses significados, Que são os veículos pelos Quais estes sujeitos comunicam, perpetuam e desenvolvem suas práticas e experiências ${ }^{(6)}$, pode levar à compreensão da cultura dos hospitais. A cultura de uma organização difunde, além de um modo de vida, um conjunto de normas, crenças e valores Que acabam por repercutir no Que é feito e no como é feito no dia a dia dessa organização(7).

Assim, entendemos Que a presente investigação pode auxiliar a desvendar os intrincados universos hospitalares, porQue possibilitará o avanço nas discussões acerca de alguns meandros da cultura organizacional, formada pelos trabalhadores da saúde, criando condições para possíveis intervenções práticas, na direção do resgate da função social e da identidade genuína destes trabalhadores. Afora isto, este estudo proporcionará um melhor entendimento do trabalho nos hospitais e como este se insere e repercute na existência dos trabalhadores, promovendo, também, uma reflexão/discussão acerca do mundo do trabalho nos hospitais, Que, por vezes, é estressante, desgastante e desanimador, mas no Qual os sujeitos encontram sentidos ao seu viver.

Diante do exposto, buscamos responder a Questão:- como os significados das relações de subsistência se evidenciam na cultura organizacional de hospitais públicos brasileiros? Para tal, objetivamos re-interpretar a interpretação de autores de teses e dissertações, com a temática cultura organizacional, sobre os significados expressos por trabalhadores da saúde acerca das relações de subsistência com o seu trabalho na cultura organizacional de hospitais públicos brasileiros.

Tomamos por referencial teórico a perspectiva subjetivista da antropologia simbólico/ interpretativa, defendida por Clifford Geertz (6.9-10) associada a idéias de diversos autores Que enfocam a temática nas distintas áreas do conhecimento.

\section{MÉTODO}

Tratou-se de um estudo de revisão. O referencial metodológico para a análise dos dados emergiu, principalmente, das concepções sobre pesquisa cultural de Geertz ${ }^{(6,9-10)}$, tanto nas Questões referentes à constituição e organização do corpus como na análise e interpretação do mesmo. A estas últimas foram também agregadas contribuições de estudiosos da Antropologia, da Administração e da Sociologia transpostas à realidade da saúde, em especial dos hospitais.

O substrato da investigação foi composto por Quatro teses ${ }^{(11-14)}$ e seis dissertações ${ }^{(15-20)}$ produzidas nos programas de pós-graduação brasileiros de diversas áreas, no período compreendido entre 2002 e 2006, Que continham a temática cultura organizacio-nal e cujo contexto era os hospitais públicos integrados à rede de prestação de cuidados de saúde do SUS. As pesquisas foram garimpados nas bibliotecas virtuais de diversas universidades brasileiras, no sistema Medline, LILACS Express, no SciELO, no Portal Periódicos (Capes), no Centro de Estudos e Pesquisas em Enfermagem (CEPEn), no Catálogo de Informações sobre pesquisas e pesquisadores em Enfermagem, (CD ROOM editado pela Associação Brasileira de Enfermagem), na bibliografia constante em estudos sobre o assunto e na rede mundial de computadores de uma maneira geral e, em especial, em sítios de busca virtuais.

Para o resgate das teses e dissertações Que não estavam disponibilizadas on line, o nome do autor foi pesquisado no Google ou na Plataforma Lattes na tentativa de descobrir seu endereço de e-mail. Quando isto foi possível, a comunicação e a solicitação deram-se desta forma, mas Quando não, houve contatos direto com os programas de Pós-graduações envolvidos ou as bibliotecas onde se encontravam armazenados os estudos, para o envio dos mesmos. Do total de teses e dissertações catalogadas apenas pelo assunto e palavras-chave "cultura organizacional" e "hospitais", Quatro não foram consideradas, porque, com a leitura, foi verificado Que não se adequavam ao requisito de aderência ao SUS, o Qual havíamos eleito como condição para integrar pesQuisa.

O corpus da pesquisa foi constituído por fragmentos textuais, Que, sob nossa ótica, evidenciaram significados Que os autores dos estudos atribuíram aos significados expressos pelos trabalhadores da saúde sobre suas relações com o trabalho, em cada cultura hospitalar. Os recortes/fragmentos textuais nos remeteram a inúmeras unidades de pensamento Que tomaram por nome a idéia Que emergiu dos mesmos durante as leituras. Estas unidades de pensamento com seus fragmentos textuais foram reagrupadas segundo 
as analogias e conexões estabelecidas entre elas e esboçaram "estruturas significantes" ou "estruturas de significação"(6).

A análise e instrumentalidade interpretativa constituiu-se na interpretação/tradução daQuilo Que os autores de teses e dissertações interpretaram sobre o significados construídos pelos trabalhadores sobre sua realidade cultural, configurando-se naQuilo Que Geertz ${ }^{(6)}$ chama de interpretação de terceira, segunda e primeira mão, respectivamente. O movimento dialógico entre estas interpretações, o referencial teórico proposto por Geertz e as idéias de outros autores sobre a temática proporcionou uma tradução, entre tantas possíveis, dos significados Que os trabalhadores da saúde atribuem ao seu trabalho.

O texto Que segue apresenta uma das estruturas de significação encontradas no decorrer da pesquisa Que trata das relações de subsistência entre os trabalhadores da saúde e seu trabalho na cultura organizacional dos hospitais públicos.

\section{RESULTADOS E DISCUSSÃO}

\section{A interpretação dos significados das relações de subsistências entre os trabalhadores da saúde e seu trabalho}

Pesquisas indicam que o salário é a maior razão para Que as pessoas trabalhem e o dinheiro é o objeto de troca mais comum entre os trabalhadores e as organizações ${ }^{(5)}$. O dinheiro, na atualidade, "fala, explica e convence" e mentalidades são edificadas ou destruídas a partir dos modos com que este circula e é distribuído. Esta verdade é aplicada tanto a pessoas que trabalham em instituições Que buscam o lucro como a outras Que estão vinculadas a instituições antagônicas à racionalidade do ganho ${ }^{(21)}$. A realização das pessoas no trabalho, inexoravelmente, depende das recompensas financeiras Que recebem, e a remuneração adequada é aquela que provoca a satisfação dos trabalhadores, mesmo Que esta noção de satisfação seja definida social e historicamente ${ }^{(22)}$. A remuneração adequada e a progressão na carreira são, também, indicadas como possíveis indicadores de Qualidade no gerenciamento de recursos humanos, mostrando Que, no cotidiano do trabalho da realidade estudada, a remuneração tem sido considerada um fator negativo ${ }^{(23)}$.

Um estudo realizado na Tureuia, na cidade de Konya, intitulado "Job satisfaction of health care staff employed at health centres in Turkey" (24) indicou Que as principais insatisfações dos trabalhadores da saúde diziam respeito à renda e às condições de improvisação no trabalho, o Que reitera a Questão salarial como motivo de descontentamento em diferentes culturas e diferentes sociedades. Isto pode ser explicado porque a cultura, apesar de ser diversa para distintos grupos sociais, possui significados Que podem ter uma direção comum, pois, a cultura "é simplesmente uma forma de falar sobre identidades coletivas"(25). Assim, esta constatação liga-se por um fio condutor à realidade do trabalho dos hospitais públicos brasileiros, conforme será abordado na seQüência.

Sabe-se Que o pagamento pelo trabalho é o Que mantém a pessoa trabalhando, pois raros são os casos em Que os indivíduos trabalham por opção ${ }^{(5)}$. Entretanto, Quando as relações com o trabalho se fundam essencialmente nesta prerrogativa e nas condições para Que esta se mantenha e sustente, temos o Que chamamos de relações de subsistência com o trabalho.

Os seguintes fragmentos textuais demonstram o trabalho como possibilidade de satisfação imanente da necessidade financeira e caminham no rumo das assertivas dispostas acima: Trabalham por necessidade financeira e pelo vínculo estável de trabalho, proporcionado por um hospital da rede pública. Observou-se no caso estudado Que o sentido do trabalho está voltado à satisfação de necessidades financeiras. À medida Que os funcionários do setor ambulatorial realizam seu trabalho por necessidade, e não por oportunidade, a natureza da tarefa é um fato limitante ao desempenho humano daqueles profissionais ${ }^{(18)}$. Nesta vertente, o comprometimento parece ser conseQüência da necessidade Que o empregado tem da organização para obter e manter as condições de sua subsistência ${ }^{(15)}$.

Estas relações de subsistência encontram eco em Marx ${ }^{(26)}$, cujas idéias contribuíram para a compreensão de alguns fenômenos organizacionais, principalmente, Quando, entre outros postulados, concebeu a doutrina de Que o trabalho ou função coletiva formava a base do mundo social e nela expôs suas idéias sobre alienação. A alienação ocorre Quando o trabalho se transforma em um artigo de compra e venda, uma mercadoria de troca, Que abandona as pessoas em uma relação instrumental com outra base da economia de valor em seu potencial de trabalho. A alienação do trabalhador no seu produto, neste canal, "significa não só Que o trabalho se transforma em objeto, assume uma existência externa, mas Que existe independentemente, fora dele e a ele estranho" e torna-se "um poder autônomo em oposição a ele: Que a vida Que deu ao objeto se torna uma força hostil e antagônica". Afora isto, o trabalho não pertence à natureza do trabalhador mas é uma condição apenas para Que ele sobreviva, isto é, o trabalho não se constitui na satisfação de uma necessidade e, sim, em um meio de satisfazer outras necessidades ${ }^{(26)}$.

A alienação, Que traduz o trabalho em símbolo de subsistência econômica, associada ao significado da condição pública do trabalho, do trabalhador e do hospital, eneuanto organização, conduz a relações Que se particularizam em uma cultura de desapego, desinteresse e acomodação em relação ao trabalho desenvolvido, conforme os achados nos estudos pesquisados: Em vista disso, os funcionários de enfermagem possuem características típicas do funcionalismo público: reatividade, passividade, acomodação, falta de perspectiva, medo de mudança, dificuldade de aceitar desafios, entre outras ${ }^{(16)}$. Segundo os entrevistados, o baixo comprometimento pode ser expresso através do não cumprimento da carga horária contratual, da não adesão aos projetos institucionais e do desinteresse na participação de Questões ditas "burocráticas"(17).

Além disso, estas relações de subsistência são reforçadas pela estabilidade Que o emprego público produz, ao mesmo tempo em Que alimenta a alienação e permite a expressão do descompromisso com o trabalho: A priorização de interesses políticos e/ou particulares em detrimento da eficácia, do profissionalismo e do bom desempenho coletivos, acaba comprometendo a seriedade com Que se deve exercer a função pública. As vantagens e os direitos proporcionados pela legislação própria do funcionalismo público se sobressaem descabidamente, Quando colocados lado a lado dos deveres e das responsabilidades contidas na mesma legislação. Nas unidades de análise, os entrevistados explicitam sua percepção, neste sentido. A estabilidade proporcionada ao servidor público somada à fragilidade da hierarQuia de valores da instituição parecem ter viabilizado Que 
elementos disfuncionais do comportamento (como a falta de comprometimento e o descaso) se instalassem e ganhassem força, trazendo conseQüências, principalmente, à eficácia dos serviços ${ }^{(15)}$.

O estudo intitulado "Gerencialismo, cultura e expectativas entre os servidores públicos de saúde"(27) realizado em um hospital da rede municipal do Rio de Janeiro identificou Que a estabilidade no trabalho constituiu-se na principal razão (38\%) para a entrada dos entrevistados no serviço público, enQuanto Que a complementação salarial atingiu a marca de $4 \%$ situando-se como a Quinta alternativa escolhida. Já sobre a principal condição para desenvolver um bom trabalho, os resultados da pesquisa indicaram Que a estabilidade contou com $6 \%$ das escolhas e a remuneração com 10\%. Com relação à concepção de trabalho, $30 \%$ dos sujeitos da pesQuisa entenderam-no como uma condição de sobrevivência.

Estes dados expostos são enfileirados aos recortes textuais abaixo recolhidos das teses e dissertações Que fizeram parte da nossa investigação e Que também mostram a Questão do emprego público associada à estabilidade e, mais ainda, às repercussões desta combinação: Atualmente, percebem Que as energias parecem Que não estão sendo mais canalizadas para o bem da empresa, mas apenas para o próprio bem do trabalhador ou de toda uma classe. Assim, a intensidade do comprometimento apresenta-se variável, conforme as necessidades e os objetivos do trabalhador, muito mais, agora, por perceber-se apoiado pela situação confortável promovida pelo regime estatutário, Que é a "estabilidade" do servidor público ${ }^{(15)}$. Ficou claro, no manancial de informações dos depoimentos, a Questão das limitações do serviço público diante das dificuldades, tais como: insubordinação, morosidade nas tomadas de decisão, crença na constância de direitos com poucos deveres ${ }^{(15)}$.

Nesta mesma linha, observa-se Que remuneração, Que no serviço público tende a ser homogênea para servidores Que desempenham funções iguais, permanece inabalada mesmo diante de comportamentos incompatíveis com o trabalho na saúde, pois a inexistência ou a existência de avaliações de desempenho pouco efetivas, Que não mensuram a produtividade e muito menos atitudes, não detém a propriedade nem o poder de reduzir ou cancelar salários. O serviço público remunera de maneira idêntica o desleixado e o cuidadoso, o dedicado e o egoísta, o produtivo e o improdutivo, o Que reforça a idéia de que todos terão igual pagamento, "porQue a ninguém interessa o resultado de trabalhos tão distintos e heterogêneos, isto é, não valeria a pena esforçar-se"(2I).

Alguns fragmentos textuais dão conta de Que, se não bastasse o emprego público, os trabalhadores da saúde ainda possuem outros empregos como forma de aumentar seu rendimento. Isto pode ser interpretado como uma insatisfação da necessidade econômica, Que se agiganta e se avoluma tanto mais Quanto é saciada. O consumismo exacerbado da sociedade capitalista vigente e o próprio achatamento salarial, Que tem acompanhado o funcionalismo público nos últimos anos, além da insatisfação com o trabalho, Que se mascara na busca da pretensa realização financeira podem ser, também, causas deste desenfreio na busca de maiores rendimentos: Outro problema é o achatamento salarial Que leva o profissional a buscar outras fontes de renda, atendendo convênios, por exemplo ${ }^{(11)}$. As enfermeiras dizem Que se trata de uma situação que decorre, além de outros fatores, do papel social Que a caracteriza, da indiferença para com a atividade, da sobrecarga de atividades pelo duplo ou triplo vínculo empregatício ${ }^{(12)}$. Desta maneira, o salário ou o próprio trabalho remunerado, "constitui apenas uma conseQüência necessária da alienação do trabalho", pois, "o trabalho aparece, não como fim em si, mas como escravo do salário"(26).

A multiciplicidade de empregos, Que reforça a idéia da subsistência, faz com Que alguns trabalhadores infrinjam normas, como por exemplo, a de horários de trabalho. Esta evidência é bem característica de uma das realidades pesquisadas em Que um hospital universitário fica a alguns metros de um hospital filantrópico e determinados funcionários da enfermagem trabalham nos dois lugares. Como os horários de entrada e saída são coincidentes, os trabalhadores saem mais cedo e chegam mais tarde no hospital universitário, porque, segundo eles, no hospital filantrópico há uma maior rigidez em relação à pontualidade e eles podem ser advertidos e até demitidos pela recorrência dos atrasos. Além do fato em si, o mais interessante é Que os funcionários não se sentem constrangidos por esta ação, pelo contrário, agem como se isto fosse absolutamente normal e pouco "escondem" esta transgressão e a mesma chega a ser banalizada e avalizada pelos colegas de trabalho. Os trabalhadores, deste modo, infringem as normas de horário e não temem a perda do emprego e a sanção das chefias, numa relação concreta de enfrentamento ao instituído, Que se reforça pela impunidade respaldada na estabilidade.

Alguns autores utilizam a expressão "autogoverno"(28,29) para designar as ações autônomas, principalmente dos médicos, em seus processos de trabalho em saúde. Neste caso, "o trabalhador de saúde opera em um espaço de 'autogoverno' Que lhe dá inclusive a possibilidade de 'privatizar' o uso deste espaço, [...], sem ter de prestar contas do que e do como está atuando"(29). Tomamos por empréstimo este termo "autogoverno" para designar as idéias Que tentamos expressar sobre as arbitrariedades cometidas pelos trabalhadores da saúde nas suas relações de subsistência com o trabalho nos hospitais, pois verificamos que eles agem independentemente daQueles preceitos Que regem os servidores e organizações públicas, estipulando e formando novos princípios de acordo com suas vontades e necessidades. Os significados destas novas configurações são construídos sob a subjetividade destes sujeitos e repassados aos demais trabalhadores e incorporados à cultura organizacional dos hospitais na forma de "transgressões permissivas".

Talvez estas transgressões ocorram pela fragilidade das normas e regras institucionais, Que, historicamente, se constituem em direitos de muitos e deveres de poucos nas organizações públicas, pela dubiedade de valor em relação às mesmas (dois pesos, duas medidas) e pela própria natureza infratora de alguns indivíduos assentada nas famosas assertivas "si hay gobierno, yo soy contra" e "regras existem para serem Quebradas": O recorte abaixo ilustra este tema: Quanto às regras e às normas do sistema organizacional institucional, no geral, eles declaram Que existem normas, mas não são explícitas, são poucas e as Que existem não são cumpridas ${ }^{(14)}$.

Mas o questionamento Que se coloca é: se o sistema hospitalar público brasileiro está calcado em uma burocracia, onde os níveis hierárquicos se mostram operantes e a rígida autoridade formal aparece, inclusive, como uma das formas de insatisfação no trabalho ${ }^{(14,17-18)}$, como pode haver regras e normas e estas não serem seguidas? Talvez, a certeza da impunidade somada à idéia de corporativismo no possível testemunho em morosos processos administrativos também sustentem esta Questão. Isto também pode estar associado à idéia do patrimonialismo, Que, em sentido amplo, 
se refere à "cultura de apropriação daQuilo Que é público pelo privado"(30). O público, nesta circunstância, e em outras da vida no trabalho, parece assumir o caráter da posse individual, isto é, "se o público é do povo e eu sou o povo, então o público é meu e eu posso dele fazer uso como bem ou mal me aprouver", instituindo uma cultura de Que o público serve, essencialmente, para atender os interesses individuais acima daqueles coletivos.

No Brasil, existe uma dificuldade acentuada em desvincular os valores familiares das funções públicas, pois, não raro, as instituições públicas foram, em sua gênese colonial, e são tomadas pelos governantes como algo de interesse próprio, com finalidades pessoais e particulares. O costume de tratar as situações de interesse geral tal Qual se abordam as Questões pessoais, com cordialidade, faz com Que tanto as relações de cunho particular como as de finalidade pública freqüentem o círculo familiar. Isto não permite Que o estado exerça sua função para superar essa ordem doméstica e familiar com o objetivo de tornar o indivíduo um cidadão portador de direitos e deveres ${ }^{(31)}$. Os seguintes recortes textuais também se configuraram no que foi exposto: Nos hospitais federais há uma cultura dos feudos, a construção da missão gira mais em função de desejos e motivações pessoais e profissionais ${ }^{(11)}$. Essa parece ser uma entre tantas outras vantagens exclusivas do regime estatutário Que motiva uma gama de indivíduos a Quererem ingressar no funcionalismo público. Ainda Que as regras, os deveres e as proibições apareçam em maior escala nos códigos e regimentos, tudo Que possa ser revertido em "benefício próprio" acabará por prioridade, no interesse e no direcionamento das condutas ${ }^{(15)}$.

Achamos interessante dispor sobre outras situações Que se apresentam como relações de subsistência com o trabalho e Que não foram explicitadas nos estudos pesQuisados, pois, são tratadas como tabus e não são discutidas nem Questionadas, apesar de serem do conhecimento corrente e um costume nas realidades hospitalares. A primeira trata do comércio informal praticado no interior dos hospitais em Que roupas, alimentos, produtos de contrabando, higiene e beleza e toda sorte de artigos são vendidos e cuja renda torna-se uma fonte alternativa de receita a alguns trabalhadores da saúde. Da mesma maneira, ou de pior maneira, conforme a mídia recorrentemente denuncia, existe, eventualmente, a cobrança por parte de médicos de procedimentos Que já estariam sendo pagos a eles pelo SUS, o Que se configura, também, em uma forma paralela de lucro. A segunda situação, não se constitui em comércio, mas, indiretamente, contribui, se não para ganho extra dos trabalhadores, para seu proveito à custa dos hospitais. É comum observarmos servidores tomarem "emprestados" materiais de curativos para a realização de procedimentos fora do hospital, bem como é usual médicos levarem seu instrumental da clínica particular para ser esterilizado nos centros de materiais e os funcionários administrativos realizarem tarefas, como declarações de imposto de renda para terceiros, no ambiente e com recursos do hospital, entre outras tantas atitudes Que se revertem em auto favorecimento dos trabalhadores. Nestes termos, entendemos o hospital como um "grande patriarca provedor" Que, mesmo tendo dificuldades em financiar suas próprias contas, acaba por financiar os empreendimentos paralelos de seus trabalhadores. O significado do uso do espaço público nesta orientação prostitui a relação dos trabalhadores com o trabalho e se constitui naQuilo Que foi falado anteriormente sobre a apropriação do público para usufruto do privado, além de ferir a ética, o respeito e a dignidade do trabalho público na saúde.

Afora isto, ações de desperdício e mau uso daquilo que é público podem ser constantemente observadas, como o gasto abusivo de água, luz, oxigênio, utilização indevida e desnecessária de produtos descartáveis e a apropriação de medicamentos para uso próprio. Estas ações, além de se constituírem em peQuenos grandes escoadouros do dinheiro público, compreendem mais uma mera relação perdulária entre trabalhadores da saúde e seu trabalho nos hospitais.

\section{CONSIDERAÇÕES FINAIS}

Os trabalhadores da saúde em seu caminho vão construindo significados Que instituem e propagam a cultura no espaço hospitalar. A impressão desta cultura é reproduzida na forma com Que estes sujeitos interagem com o trabalho estabelecendo com ele vários tipos de relações. As relações de subsistência entre os trabalhadores da saúde e seu trabalho são traduzidas/interpretadas pela alienação com o trabalho, em Que atitudes de descompromisso, desinteresse e falta de dedicação são constantes. A remuneração surge como um aspecto simbólico Que funciona como veículo de insatisfação econômica e Que alavanca a multiplicidade de empregos na área hospitalar. A estabilidade no emprego parece ser um fator Que mantém as relações de subsistência, pela certeza da continuidade do salário e do emprego mesmo diante da falta de empenho no trabalho. A estabilidade também alimenta ações Que estimulam a transgressão de normas e facilita os autogovernos, através da invasão da esfera pública dos hospitais pelos interesses privados dos trabalhadores.

Diante destes resultados, a interrogação Que não cala é aQuela voltada à ética, ou melhor, à falta de ética dos trabalhadores da saúde ao empreenderem esta caminhada contra os hospitais públicos Que lhe acolhem e sustentam. Quais os valores morais Que estão em jogo no trabalho Quando o senso de dever parece já ter sucumbido diante das relações meramente econômicas e perdulárias Que assombram os hospitais públicos brasileiros?

O compromisso com o trabalho na saúde, acima de Quaisquer outras prerrogativas deveria se constituir na marca distintiva dos trabalhadores da saúde, não em sua acepção missionária, mas no sentido da responsabilidade profissional. Pois, como afirma Geertz o mundo cotidiano no Qual se movem os membros de Qualeuer comunidade, seu campo de ação social, não é habitado por homens Quaisquer, sem rosto, sem Qualidades, "mas por homens personalizados, classes concretas de pessoas determinadas, positivamente caracterizadas e adequadamente rotuladas", cujos sistemas de símbolos não são dados pela natureza das coisas, mas, sim, pela sua construção histórica, Que se mantém socialmente ${ }^{(6)}$.

A tradução/interpretação da interpretação dos autores de teses e dissertações, sobre o conjunto de significados externados pelos trabalhadores da saúde na relação com o seu trabalho, desvela um recorte da cultura organizacional dos hospitais públicos brasileiros e pode auxiliar na construção de caminhos Que conduzam à compreensão destas organizações chamadas hospitais e suas complexas interligações, cujas particularidades sempre instigarão aqueles pesquisadores comprometidos com o conhecimento sobre o processo de condução destes espaços. 


\section{REFERÊNCIAS}

1. Organização Mundial da Saúde. Trabalhadores de saúde: um perfil global. Genebra: OMS; 2006.

2. Ministério da Saúde (BR). Departamento de Informática do SUS. [citado em 09 jun 2008]. Disponível em: http:// tabnet.datasus.gov.br/cgi/deftohtm.exe?ams/cnv/namsrbr.def

3. Ministério da Educação (BR). Secretaria de Ensino Superior. Coordenação de Hospitais Universitários. Sistema de informações dos HUs federais. [citado em 24 jun 2008]. Disponível em: http://portal.mec.gov.brsesuindex.php? option $=$ content $\&$ task $=$ category\&sectionid $=10 \& i d=97 \&$ Itemid $=30 \mathrm{l}$.

4. Vaghetti HH. As perspectivas de um retrato da cultura organizacional de hospitais públicos brasileiros: uma tradução, uma bricolagem [tese]. Florianópolis: Programa de Pósgraduação em Enfermagem, Universidade Federal de Santa Catarina; 2008.

5. Bom Sucesso EP. Relações interpessoais e Qualidade de vida no trabalho. Rio de Janeiro: Qualitymark Ed; 2003.

6. Geertz, C. A interpretação das culturas. Rio de Janeiro: LTC; 1989.

7. Freitas ME. Cultura organizacional: evolução e crítica. São Paulo: Thomson Learning; 2007.

8. Smircich L. Concepts of culture and organizational analysis. Adm Sci Quarterly 1983; 28(3): 339-58.

9. Geertz C. Nova luz sobre a antropologia. Rio de Janeiro: Jorge Zahar; 200I.

10. Geertz C. O saber local: novos ensaios em antropologia interpretativa. Petrópolis: Vozes; 2001.

11. Artmann E. Démarche Stratégique (Gestão Estratégica hospitalar): um enfoque Que busca mudança através da comunicação e da solidariedade em rede [tese]. Campinas: Faculdade de Ciências Médicas, Universidade Estadual de Campinas; 2002.

12. Guariente MHD. Articulação da atividade investigativa com a prática profissional: processo e produto de enfermeiras apoiadas por um núcleo de pesquisa [tese]. Ribeirão Preto: Escola de Enfermagem de Ribeirão Preto, Universidade de São Paulo; 2006.

13. Menezes MFB. A cultura administrativa do gerenciamento de enfermagem em unidade oncológica: um estudo etnográfico [tese]. Rio de Janeiro: Escola de Enfermagem Anna Nery, Universidade Federal do Rio de Janeiro; 2003.

14. Prochnow AG. O exercício da gerência do enfermeiro: cultura e perspectivas interpretativas [tese]. Rio de Janeiro: Escola de Enfermagem Anna Nery, Universidade Federal do Rio de Janeiro; 2003.

15. Ávila GF. Elementos da cultura de um hospital universitário: repercussões no comportamento organizacional [dissertação]. Rio Grande: Universidade Federal do Rio Grande; 2006.

16. Lima MBBPB. A gestão da Qualidade e o redesenho de processos como modelo de desenvolvimento organizacional em Hospitais Públicos Universitários: o caso do Hospital de Clínicas da UNICAMP [dissertação]. Campinas: Faculdade de Engenharia
Mecânica, Universidade Estadual de Campinas; 2006.

17. Macedo AN. Autonomia profissional e uso da informação no hospital: discutindo a cultura organizacional [dissertação]. Rio de Janeiro: Departamento de Administração e Planejamento em Saúde, Fundação Osvaldo Cruz, Escola Nacional de Saúde Pública; 2006.

18. Salgado SPV. Importância da cultura organizacional como fatores determinantes nado pessoal de enfermagem do Hospital Universitário Antonio Pedro [dissertação]. São Paulo: Escola de Administração de Empresas de São Paulo, Fundação Getúlio Vargas; 2003.

19. Verbist CF. A gestão da hospitalidade sob a perspectiva da humanização dos hospitais - um estudo de caso [dissertação]. Caxias do Sul: Programa de Mestrado Acadêmico em Turismo, Universidade de Caxias do Sul; 2006.

20. Viana RV. A humanização no atendimento à saúde: construindo uma nova cultura [dissertação]. Rio de Janeiro: Escola Nacional de Saúde Pública Sérgio Arouca, Fundação Osvaldo Cruz; 2004.

21. Campos GWS. Subjetividade e administração de pessoal: considerações sobre modos de gerenciar o trabalho em equipes de saúde. In: Merhy EE, Onocko R, organizadores. Agir em saúde: um desafio para o público. São Paulo: Hucitec; 2007. p. 229-66.

22. Pires DEP. O processo de trabalho em saúde no Brasil no contexto das transformações atuais na esfera do trabalho: estudo em instituições escolhidas [tese]. Campinas (SP): Departamento de Sociologia do Instituto de Filosofia e Ciências Humanas, Universidade Estadual de Campinas; 1996.

23. Kurganct P, Melleiro MM, Tronchin DMR. Indicadores para avaliação de Qualidade do gerenciamento de recursos humanos em enfermagem. Rev Bras Enferm 2008; 6I (5): 539-44.

24. Bodur $\mathrm{S}$. Job satisfaction of health care staff employed at health centres in Turkey. Occup Med 2002; 52(6): 353-5.

25. Kuper A. Cultura: a visão dos antropólogos. Bauru: EDUSC; 2002.

26. Marx K. Manuscritos econômico-filosóficos. São Paulo: Matin Claret; 2004.

27. Vaitsman I. Gerencialismo, cultura e expectativas entre os servidores públicos de saúde. Rev Adm Pública 200 I; 35(1): 7-27.

28. Merhy E. Em busca do tempo perdido: a micropolítica do trabalho vivo em saúde. In: Merhy E, Onocko RT, organizadores. Agir em saúde: um desafio para o público. São Paulo: Hucitec; 2007. p. $71-112$

29. Campos GWS. A saúde pública e a defesa da vida. São Paulo: Hucitec; 1994.

30. Martins HF. A ética do patrimonialismo e a modernização da administração pública brasileira. In: Motta FCP, Caldas MP, organizadores. Cultura organizacional e cultura brasileira. São Paulo: Atlas; 1997.

31. Hollanda SB. Raízes do Brasil. Rio de Janeiro: José Olympio; 1986 